\title{
Территориальные и отраслевые аспекты инновационного подхода технологического развития вертолётостроительного производства Дальнего Востока России
}

\author{
Пётр Бровко, Борис Карастелёв, Юрий Якубовский* \\ Дальневосточный федеральный университет, г. Владивосток, Россия
}

Информация о статье
Поступила в редакцию:
16.03 .2019
Принята
к опубликованию:
27.07 .2019
УДК 330
JEL M31

Ключевье слова: технологическое развитие, инновационный подход, вертолётостроительное производство, Дальний Восток, центр технологических компетенций

\section{Keywords:}

technological development, innovative approach, helicopter production, the Far East, the center of technological competence

\begin{abstract}
Аннотация
В работе представлено обоснование необходимости перехода вертолётостроительного производства Дальнего Востока России на инновационный подход технологического развития, который позволит преодолеть влияние территориальных и отраслевых негативных факторов и закрепиться на динамичных рынках Азиатско-Тихоокеанского региона. Обозначены перспективы роста экономики России $и$ вертолётостроения, в частности, за счет выхода на рынки Азиатско-Тихоокеанского региона. В качестве организационного инструмента, способствующего продвижению инновационных технологий в вертолётостроительном производстве, предлагается создание центра технологических компетеничй.
\end{abstract}

Territorial and Sectoral Aspects of Innovation Approach Technological Development of Helicopter Production Russian Far East

Peter Brovko, Boris Karastelev, Yuriy Yuakubovskiy

\section{Abstract}

It was found that the far East of Russia has unique competitive advantages, the main of which is the neighborhood with the dynamically developing countries of the Asia-Pacific region, the economic rate of which over the past decade exceeds the global average. The strategic task facing the Russian economy is integration into consolidation in the markets of the Asia-Pacific region, as producers of high-tech products. This necessitates the development of high-tech industries in the Russian far East, which include helicopter construction. In the helicopter industry in Russia there is a lag the world's leading companies in the use of innovative technologies of design, production and after-sales service. In addition, the work found that there are several problems in the industry: the limited size of the domestic market, the reduction of public funding for new developments, the lack of competence of staff to work in the global market. In the far East, this situation is complicated by the influence of negative regional factors: high costs in the economy, a long, outflow of population,

\footnotetext{
* Автор для связи: E-mail: yakubovskiy.yuv@dvfu.ru DOI: https://dx.doi.org/10.24866/2311-2271/2019-3/115-125
} 
remoteness from traditional markets and suppliers, the raw material nature of the economy. The paper substantiates the need for the transition of helicopter production in the Far East of the Russian Federation to an innovative approach to technological development, which will overcome the influence of territorial and sectoral negative factors. The components of the proposed innovative approach are the introduction into production of products with high export potential, building cooperation with partners from the Asia-Pacific region, technological renewal of the production system, establishing cooperation with scientific and educational institutions, small and medium-sized businesses. A tool for the implementation of a new approach to the technological development of helicopter production in the Far East of Russia will be the creation of a center Of technological competencies, which will allow for cooperation between the production enterprises of the region and scientific and educational institutions, which will contribute to the generation of new knowledge and its practical use in production activities The rapid introduction of innovative technologies will increase the competitiveness of the Russian helicopter industry, which will strengthen its position in the Asia-Pacific region.

\section{Введение}

Вертолётостроительное производство, как сектор высокотехнологичного машиностроения, занимает особое место в экономике Дальнего Востока России: выпуск вертолётной техники относится к производствам высокой добавленной стоимости, что значительно повышает социально-экономические показатели территории (отчисления в бюджет, число высококвалифицированных рабочих мест, развитие инфраструктуры). При этом развитие вертолётостроительного производства на Дальнем Востоке сдерживается из-за недостаточного использования в деятельности производственной системы технологических инноваций, которые на практике формируют конкурентные преимущества. В тоже время, экономике региона присущи высокие затраты по условиям отдаленности от центра, своеобразности климата, неразвитой инфраструктуры и т.д. Недостаточное использование инноваций в производственной деятельности снижает конкурентоспособность вертолётостроительного производства Дальнего Востока РФ на отраслевом сегменте, что не позволяет реализовать открывающиеся возможности выхода на перспективные рынки АзиатскоТихоокеанского региона.

Причиной сложившейся ситуации является укоренившаяся производственная система, которая не учитывает современные особенности технологического развития отрасли, иограничения с которыми предприятия сталкиваются при внедрении современных технологических инноваций. Для перехода на новую платформу технологического развития необходимо проведение дополнительных исследований по использованию цифровых технологий.

Целью данного исследования является обоснование перспективности перехода вертолётостроительного производства Дальнего Востока России на инновационный подход технологического развития.

Вопросы экономики Дальнего Востока России изучают П.А. Минакир, А.Н. Демьяненко, О.М. Прокопало, Н.В. Ломакина, В.В. Ивантер, В.И. Ишаев, Д.Н. Кувалин, В.К. Заусаев, А.П. Латкин и др $[4,6,7,11]$. Следует отметить, что проблеме инновационных факторов технологического развития промышленности региона уделяется недостаточно внимания. Стратегическое значение Дальнего Востока и его авиационной промышленности для экономики России обуславливают инновационный характер применяемых подходов обеспечения их технологического совершенствования. В работе предпринята попытка определения составляющих инновационного подхода технологического развития вертолётостроительного производства на Дальнем Востоке. 


\section{Методология и методы исследования}

Методология и методический инструментарий исследования базируются на сопоставлении реально осуществляемой стратегии технологического развития вертолётостроительного производства в сопровождении территориальнорегиональных и отраслевых негативных факторов с развитием современного авиастроения. В основе метода исследования: экономико-статистический, сравнительный анализ (при сопоставлении показателей деятельности производителей вертолётной техники), логическое обоснование.

\section{Роль Дальнего Востока в экономике России}

Президент Российской Федерации В.В. Путин в своём Послании Федеральному собранию в 2013 г. определил развитие Дальнего Востока национальным приоритетом на весь XXI век. Стратегическая значимость поставленной задачи определяется следующими конкурентными преимуществами, которыми обладает Дальневосточный федеральный округ (далее - ДФО) $[2,4,11]$.

1. Непосредственное соседство со странами Азиатско-Тихоокеанского региона (далее - АТР), которые являются наиболее динамичной частью мировой экономики. На долю АТР приходится более $50 \%$ мирового ВВП и прямых иностранных инвестиций, темпы роста экономик стран АТР превышают среднемировые в 2-3 раза, что способствует увеличение совокупного спроса в этих странах на продукты российского экспорта. В условиях санкций со стороны западных стран расширение рынков сбыта товаров повышает устойчивость экономики. Кроме того, рынки АТР рассматриваются как перспективные для российского наукоёмкого экспорта, прежде всего военной продукции, что при сокращении Государственного оборонного заказа является одним из решений проблемы загрузки свободных мощностей предприятий.

2. Наличие огромных запасов природных ресурсов: нефти (около 20 млрд тонн), природного газа (более 30 трлн м³), редкоземельных металлов (20\% общероссийских запасов), алмазов ( $80 \%$ российских разведанных балансовых запасов), золота (около 5000 тонн), леса (30\% общероссийских запасов), рыбы и морепродуктов (26 млн тонн) и др. [7, 11]. Разработка природных ресурсов Дальнего Востока способна стать основой для развертывания в регионе новых высокодоходных производств, которые обеспечат поступление дополнительных доходов в государственный бюджет.

3. Транзитный потенциал территории. Использование транспортной системы (Транссибирской и Байкало-Амурской магистралей, Северного морского пути) и инфраструктуры региона позволяют сократить доставку грузов из Азии в Европу на 10-15 дней. Использование транзитного потенциала является дополнительным источником доходов в экономике страны.

Кроме того, в работе программы развития Дальнего Востока могут быть использованы как инструменты стимулирования экономики страны в условиях кризиса, так как реализация инвестиционных проектов на дальневосточной территории создаст массовый спрос на продукцию отечественных производителей в условиях сокращения экспорта и спроса в западных регионах [7].

Трансформация имеющихся у Дальнего Востока конкурентных преимуществ в поступательное социально-экономическое развитие сдерживается, имеющимися у ДФО проблемами [2, 6, 7, 11]:

- высокие затраты в экономике региона, обусловленные более высокой заработной платой, дороговизной социальной инфраструктуры и услуг есте- 
ственных монополий, что налагает ограничения на ведение бизнеса в дальневосточном регионе;

- низкая плотность населения и его многолетний отток, что создаёт дефицит трудовых ресурсов, особенно высококвалифицированных;

- удаленность от внутренних рынков сбыта и высокие транспортные тарифы, что негативно сказываются на конкурентоспособности производимых товаров;

- сырьёвой характер экономики региона, вызванный его ориентацией на экспорт в соседние страны природных ресурсов, что сдерживает развитие обрабатывающих производств.

Чтобы разрешить имеющиеся проблемы, Правительством Российской Федерации реализуются мероприятия по формированию новой модели развития территории Дальнего Востока, которая должна обеспечить опережающий рост социально-экономическое состояния региона. Новая модель о будет эффективна только в том случае, если одновременно будет создан высокотехнологичный промышленный комплекс (самолёто- и вертолетостроение, арктическое судостроение, переработка нефти и газа, аэрокосмический центр), выпускающий продукцию с высокой добавленной стоимостью. Одним из элементов этого комплекса является вертолётостроительное производство.

\section{Особенности развития российского вертолётостроения}

Россия по праву считается ведущей вертолётостроительной державой. Российскими предприятиями произведено свыше 26 тыс. машин, что составляет треть всех выпущенных в мире вертолётов. До распада СССР российское (советское) вертолётостроение занимало до четверти мирового рынка. После рыночных реформ объёмы производства на предприятиях вертолётостроения резко снизились от нескольких сотен штук вертолётов до нескольких машин в год. Многие предприятия долгое время простаивали без достаточной загрузки мощностей. Главным фактором падения производства было сокращение государственного заказа на продукцию вертолётостроительных предприятий и утрата традиционных рынков сбыта вследствие распада социалистического блока стран.

Предприятия оказались разобщенными: был ликвидирован единый орган управления - Министерство авиационной промышленности. Это заставило предприятия вести разорительную внутриотраслевую конкурентную борьбу. Были нарушены многие хозяйственные связи между предприятиямисмежниками, которые складывались годами, в особенности это затронуло предприятия, оказавшиеся в разных государствах, образовавшихся в начале 90х гг. прошлого века.

В середине 2000-х гг. произошел рост объёмов производства и реализации вертолётной техники в России. Главным фактором, оказавшим положительное воздействие на развитие вертолётостроения, является консолидация предприятий в единую хозяйственную структуру. Для развития отечественного вертолётостроения, повышения его эффективности, формирования научнотехнического задела в соответствии с Указами Президента РФ от 29.11.2004 г. № 1481 и от 11.08.2007 г. № 1038 под управлением АО «ОПК Оборонпром» была сформирована интегрированная структура предприятий - разработчиков и производителей вертолётной техники - холдинг АО «Вертолеты России» [9]. 
Несмотря на положительные сдвиги в развитии российского вертолётостроения, оно пока ещё существенно отстаёт от зарубежных конкурентов по показателям организационной и производственной эффективности (табл. 1).

Таблица 1

Показатели хозяйственной деятельности мировых производителей вертолётной техники

\begin{tabular}{|c|c|c|c|c|c|}
\hline \multirow[b]{2}{*}{ Производитель } & \multicolumn{5}{|c|}{ Показатели } \\
\hline & $\begin{array}{l}\text { Поставлено } \\
\text { машин, штт. }\end{array}$ & $\begin{array}{c}\text { Выручка млрд } \\
\text { долл. США }\end{array}$ & $\begin{array}{c}\text { Прибыль от } \\
\text { продажс, млрд } \\
\text { долл. США }\end{array}$ & $\begin{array}{c}\text { Затраты на } \\
\text { НИОКР, млрд. } \\
\text { долл. США }\end{array}$ & $\begin{array}{c}\text { Производи- } \\
\text { тельность труда } \\
\text { тыс. долл. США } \\
\end{array}$ \\
\hline \multicolumn{6}{|c|}{ AO «Вертолеты России» } \\
\hline 2012 & 290 & 4,04 & 0,64 & 0,16 & 96,4 \\
\hline 2014 & 271 & 4,03 & 0,67 & 0,192 & 94,3 \\
\hline 2016 & 196 & 3,2 & 0,41 & 0,043 & 70,3 \\
\hline \multicolumn{6}{|c|}{ Airbus Helicopter } \\
\hline 2012 & 475 & 7,3 & 0,4 & 0,38 & 383,6 \\
\hline 2014 & 471 & 8,54 & 0,54 & 0,42 & 371 \\
\hline 2016 & 418 & 7,36 & 0,38 & 0,35 & 327 \\
\hline \multicolumn{6}{|c|}{ Augusta Westland } \\
\hline 2012 & $\mathrm{H} /$ Д & 5,4 & 0,6 & 0,64 & 420,6 \\
\hline 2014 & $\mathrm{H} /$ Д & 5,73 & 0,54 & 0,61 & 436 \\
\hline 2016 & $\mathrm{H} /$ д & 3,99 & 0,47 & 0,39 & 336 \\
\hline \multicolumn{6}{|c|}{ Bell } \\
\hline 2012 & 261 & 4,2 & 0,63 & 0,18 & 353,2 \\
\hline 2014 & 249 & 4,24 & 0,52 & 0,15 & 487 \\
\hline 2016 & 171 & 3,2 & 0,38 & 0,086 & 320 \\
\hline
\end{tabular}

Источник: составлено авторами на основе $[12,13,14,15]$

Российское вертолётостроение уступает крупным мировым субъектами по показателю производительности труда в 3-4 раза. Это обусловлено различиями в системе организации производства и использовании передовых технологий на российских и зарубежных предприятиях.

За время кризиса российской авиационной промышленности в технологическом развитии мирового авиастроения, и вертолётостроения, в частности, произошли существенные изменения, коренным образом изменившие структуру авиастроительных компаний и рынков. К этим особенностям технологического развития современного вертолётостроения относятся:

1) расширение функциональных возможностей вертолётной техники за счет совершенствования аэродинамической компоновки, применения в её конструкции современных материалов и бортовых систем, что привело к увеличению стоимости разработки и производства воздушных судов в несколько раз;

2) удорожание вертолётной техники и повышение её функциональных возможностей приводит к сокращению военных закупок, что вынуждает производителей наращивать активность на гражданских сегментах рынка, в том числе на основе применения «двойных технологий»;

3) консолидация авиастроительных компаний привела к тому, что конкуренция практически осуществляется не между компаниями, а между государствами, где они дислоцируются, что обуславливает усиление государственной поддержки авиастроительной промышленности, особенно в проведении фундаментальных и прикладных исследований;

4) инновационные технологии создания авиационной техники (интегрированные компьютерные технологии проектирования и управления, обрабатывающие центры, лазерное оборудование и др.) вызвали структурное преобразование системы организации и управления производством, передачу значительной части технологических этапов внешним поставщикам на аутсорсинг; 
5) развитие технологий автоматизированного проектирования и инженерного анализа (CAD и CAE- технологий), робототехники, а также аддитивных технологий дают возможность наладить мелкосерийный выпуск конкурентоспособной по стоимости продукции по индивидуальным заказам потребителей;

6) ужесточение требований к воздействию авиационного транспорта на окружающую среду и необходимость повышения рабочего ресурса элементов воздушного судна выступили главным фактором увеличения применения в конструкции авиационной техники композитных материалов;

7) повышение требований к качеству авиационной техники и удорожание её стоимости обусловили переход от продажи отдельного продукта к продаже жизненного цикла изделия. Это вызвало развитие технологий управления жизненным циклом изделия, позволяющих оптимизировать системы послепродажного технического обслуживания и логистики снабжения эксплуатантов.

В российском вертолётостроении продолжает действовать система производства, которая опирается преимущественно на потенциал технологий 4-го технологического уклада, что предопределяет трудности при выпуске гражданской продукции и осуществление послепродажного обслуживания реализуемой техники.

Проблему технологического отставания отечественного вертолётостроения усугубляют следующие негативные отраслевые факторы $[3,5,10]$ :

- ограниченность размеров внутреннего рынка обуславливает необходимость при создании новых, инновационных образцов техники ориентироваться на внешний рынок;

- сокращение доступности государственного финансирования и высокая стоимость финансовых ресурсов на внутреннем рынке снижает возможности по организации инвестиций для новых разработок;

- исчерпание потенциала традиционных авиационных технологий и слабые позиции России в технологиях будущего технологического уклада;

- недостаточность компетенций у персонала для работы на глобальном рынке.

Преодоление имеющихся в сегменте отрасли негативных факторов позволит создать выход на рынки Азиатско-Тихоокеанского региона, плацдармом для которого является вертолётостроительное производство Дальнего Востока России.

Инновационный подход технологического развития вертолётостроительного производства Дальнего Востока РФ

В настоящее время на Дальнем Востоке осуществляется выпуск преимущественно военной вертолётной техники по государственному оборонному заказу, предприятия пользуются широкой государственной поддержкой. Доля гражданской продукции незначительна. Это сдерживает поступательное развитие вертолётостроительного производства поскольку не позволяет интегрироваться в экономику АТР. Чтобы повысить эффективность вертолётостроительного производства в дальневосточном округе, следует перейти на новую стратегию технологического развития, нивелирующую негативные территориальные и отраслевые факторы. К целевым составляющим этой стратегии предлагается отнести: 
1) внедрение в производство продукции с высоким экспортным потенциалом, особенно на рынках Азиатско-Тихоокеанского региона, увеличение доли гражданского производства;

2) переход производственной системы на технологии 5-го и 6-го технологических укладов;

3) развитие кооперации с малым и средним бизнесом территории;

4) построение совместно с научными и образовательными территориальными организациями инновационной системы научных исследований и подготовки кадров для нужд вертолётостроительного производства;

5) осуществление совместных проектов по освоению морских территорий с зарубежными партнерами с целью привлечения дополнительных инвестиций и необходимых компетенций.

Инновационный подход технологического развития вертолётостроительного производства на Дальнем Востоке позволит:

- осуществлять разработку и производство перспективных видов воздушных судов, востребованных на рынках АТР в целях повышения окупаемости реализуемых холдингом проектов;

- привлекать дополнительные инвестиции для реализации совместных проектов;

- сократить затраты путем увеличения масштабов производства вертолетной техники. Это ослабит присущую ДФО высокозатратность экономики;

- выстроить эффективную систему подготовки кадров, обладающих компетенциями для работы на глобальном рынке;

- организовать отвечающую современным требованиям систему научных исследований для нужд высокотехнологичного производства в совокупности с институтами ДВО РАН и университетами ДФО.

В высокотехнологичных, наукоёмких производствах невозможно создать передовые образцы техники и технологий без проведения комплексных научных исследований, которые позволяют установить возможность использования новых закономерностей, явлений, свойств материального мира в определенном виде техники и производственных технологиях. В СССР в авиационной промышленности прикладные и поисковые научно-исследовательские работы проводились в широкой сети научно-исследовательских институтов (ЦАГИ, ВИAМ, ЦИАМ, ЛИИ, НИАТ, организации Академии наук). Научное обеспечение охватывало все стадии создания новой техники: научно-исследовательские работы, проектирование и производство.

Научно-исследовательские работы устанавливали возможность использования открытого фундаментальной наукой явления, принципа или свойства в создании перспективных видов авиационной техники. На стадии проектирования исследовались возможности использования известных научных закономерностей и принципов для разработки конкретных образцов авиационной техники, решались проблемы, возникающие при проектировании новой машины. На стадии подготовки производства целью научных исследований являлась разработка новых, прогрессивных методов, прогрессивного оборудования и оснастки, а также разработка процессов как контроля качества, так и организации процессосности позиций и управление созданием нового продукта.

Научные работы, проводившиеся на каждой стадии, были взаимосвязаны: воплощение в конструкции изделия результатов научно-исследовательских работ приводила к поиску путей применения их в производстве. Например, 
применение нового материала в конструкции изделия требует проведения работ по поиску оптимальных технологических режимов его обработки, проектирования специального технологического оснащения и т.д.

В настоящее время делаются попытки выстроить систему управления технологическим развитием в авиационной промышленности. Федеральным законом от 04 ноября 2014 года № 326-Ф3 создан Национальный исследовательский центр «Институт имени Н.Е. Жуковского», функции которого сводятся к организации и выполнению научно-исследовательских работ по разработке новых технологий в приоритетных направлениях развития авиационной техники, ускоренному внедрению их в производство, использованию новых научных достижений в области авиастроения в интересах развития экономики Российской Федерации [1].

Следует отметить, что в структуре созданного Национального исследовательского центра не представлены научно-исследовательские организации, которые занимаются разработками в области авиационного материаловедения и совершенствованием производственных технологий. Новые материалы и новые производственные технологии являются ключевым фактором технологического развития промышленности [8].

Удаленность ДФО от ведущих научных и образовательных центров является сдерживающим фактором технологического развития вертолётостроительного производства. Поэтому для обеспечения реализации инновационного подхода технологическим развитием необходимо в округе выстроить эффективную систему научных исследований и подготовки кадров.

В настоящее время Правительством Российской Федерации предпринимаются меры по формированию научно-исследовательской и инновационной инфраструктуры на территории округа. В г. Владивостоке на о. Русский построен Дальневосточный федеральный университет, на базе которого создается уникальная экосистема, обеспечивающая проведение научноисследовательских работ в интересах ведущих отечественных и зарубежных компаний и их коммерциализацию. Создаваемая инновационная экосистема должна опираться на продуктивное сотрудничество между научноисследовательскими организациями и реальным сектором экономики.

В вертолётостроительном производстве в качестве инновационного инструмента сотрудничества между научно-исследовательскими организациями и производственными предприятиями предлагается создание центра технологических компетенций (далее - ЦТК), который представляет собой площадку, действующую на базе определенного предприятия, целью которой является формирование и развитие компетенций создания ценности в сфере новых инновационных технологий, определяющих лидирующие позиции предприятия в долгосрочной перспективе, а также обеспечивающий сопровождение их внедрения в практику.

ЦТК предлагается решать пять основных задач: поиск источников развития новых, передовых технологий, мобилизационную, согласующую, экспертную и обучения. Первая задача - поиск источников развития новых технологий - предполагает отбор технологических разработок и компетенций среди научных организаций и инжиниринговых фирм партнеров, взаимодействие с которыми позволит предприятию развивать свои компетенции в инновационных производственных технологиях. Помимо внешних источников развития инновационных технологий центру технологических компетенции необходимо ис- 
кать источники внутри предприятия, среди своего персонала. Одной из главных задач ЦТК является обеспечение процессов взаимодействия между представителями внешних организаций и работниками предприятия в решении проблем, возникающих при внедрении в производственную деятельность технологических инноваций.

Мобилизационная задача решается путем выработки практических шагов по внедрению инноваций, поиска необходимых организационных и финансовых ресурсов, выявлении сотрудников, склонных к инновационной деятельности, создании условий для их плодотворной работы.

Согласующая задача включает в себя решение вопросов поиска компромисса между различными влиятельными группами внутри предприятия при внедрении новой, инновационной технологии. Инновационная технология, как правило, вызывает изменения в производственном процессе предприятия, что отражается на интересах различных групп работников. В результате работникам свойственна практика сопротивления проводимым изменениям. Решить проблему, опираясь только на административные методы не всегда возможно. Центр технологических компетенций будет разрабатывать приемлемое разрешение данных проблем.

Экспертная задача состоит в решении вопросов прогнозирования направлений технологического развития авиационной промышленности, проведения экспертизы уровня прогрессивности предлагаемых к внедрению инновационных технологий, обоснованности потребности в ресурсах, возможности внедрения инноваций в условиях конкретного предприятия.

Задача обучения заключается в разработке образовательных программ и рекомендаций по организации процесса обучения персонала в целях овладения навыками и умениями, которые необходимы для освоения технологических инноваций в реальной производственной деятельности.

Создание центра технологических компетенций будет способствовать повышению результативности инновационной деятельности в вертолётостроительном производстве Дальнего Востока России, а также позволит взаимодействовать в сотрудничестве с научными организациями и университетами региона.

\section{Заключение}

Обобщая выше сказанное можно сделать следующие выводы.

Для решения стратегических задач развития Дальнего Востока и ответа на вызовы, стоящие перед российским вертолётостроением необходимо формирование инновационного подхода технологического развития вертолётостроительного производства в регионе, основу которого должны составить инновационные инструменты управления, учитывающие региональную специфику и отраслевые факторы.

В качестве инновационного инструмента сотрудничества между научноисследовательскими организациями и производственными предприятиями предлагается создание центра технологических компетенций, его активная деятельность во взаимодействии с институтами РАН и университетами будет способствовать формированию новых научных знаний и совершенствованию системы образования на Дальнем Востоке. Центр технологических компетенций выступит концентратором творческих напряжений, способный генерировать импульсы по созданию высокотехнологичных производств в ДФО; 
Для отечественного вертолётостроения инновационное развитие его дальневосточного сегмента будет способствовать выходу на динамичные рынки Азиатско-Тихоокеанского региона, получению доступа к дополнительному капиталу и новым технологическим и организационным компетенциям.

\section{Список источников / References}

1. Федеральный закон от 4 ноября 2014 г. $\quad$ N 326-Ф3 "О Национальном исследовательском центре "Институт имени Н.Е. Жуковского" [Электронный ресурс] - Режим доступа: http://base.garant.ru/70781534/

2. Государственная программа Российской Федерации «Социально-экономическое развитие Дальнего Востока и Байкальского региона»: утверждена постановлением Правительства РФ от 15.04.2014 № 308 (в ред. от 30.03.2017) - [Электронный ресурс] - Режим доступа: https://minvr.ru/upload/iblock/1cd.pdf

3. Стратегия развития авиационной промышленности Российской Федерации на период до 2030 года (проект, в редакции на 28 ноября 2016 г.) [Электронный ресурс] Режим доступа: http://minpromtorg.gov.ru/docs/\#!strategiya_razvitiya_aviacionnoy_promyshlennosti_ross iyskoy_federacii_na_period_do_2030_goda

4. Восток России: проблемы освоения - преодоления пространства: монография/ под ред. В.А. Крюкова и В.В. Кулешова. - Новосибирск: Издательство ИЭОПП СО PAH, 2017. $-484 \mathrm{c}$.

5. Дутов А.В., Клочков В.В., Рождественская С.М. Большие вызовы для авиации, авиастроения и развития авиационных технологий: монография/А.В. Дутов, В.В. Клочков, С.М. Рождественская. - М.: НИЦ «Институт им. Н.Е. Жуковского», 2017. $-125 \mathrm{c}$.

6. Ишаев В.И., Ивантер В.В., Кувалин Д.Б. Экономика Дальнего Востока и Байкальского региона: государственный подход: монография/В.И. Ишаев, В.В. Ивантер, Д.Б. Кувалин. - М.: МАКС Пресс. - 2015. - 264 с.

7. Латкин А.П. Российский Дальний Восток: предпосылки и условия привлечения иностранных инвестиций: монография/ А.П. Латкин, В.А. Казакова, Т.В. Евсеева; под общ. ред. проф. А.П. Латкина. - Владивосток: Изд-во ВГУЭС, 2015. - 240 с.

8. Новые производственные технологии: публичный аналитический доклад. - М.: Издательский дом «Дело» РАНХ и ГС, 2015. - 272 с.

9. Реус А., Зинченко А.П., Крайчинская С.Б, Талянский Д. О методе управления знаниями в процессах интеграции машиностроительной корпорации/ А.Г. Реус, А.П. Зинченко, С.Б. Крайчинская, Д. Талянский. - М.: Издательский дом «Дело» РАНХиГС, 2011. - 80 с.

10. Российская авиационная отрасль: переломный момент/ Исследование Strategy Partners Group - [Электронный pecypc] - Режим доступа: http://strategy.ru/UserFiles/File/Doklad/2013_Russian\%20aviation.pdf

11. Российский Дальний Восток на пути в будущее: научный доклад/ под ред. П.А. Минакира; Институт экономических исследований ДВО РАН. - Хабаровск: ИЭИ ДВО PAH, 2017. - 395 c.

12. Сайт АО «Вертолеты России» [Электронный ресурс] - Режим доступа: http://www. russiauhelicpters.aero.ru.

13. Сайт компании Airbus Helicopter [Электронный ресурс] - Режим доступа: http://www.airbus-group.com.

14. Сайт компании Bell [Электронный ресурс] - Режим доступа: http://www.bellhelicopter.textron.com.

15. Сайт компании Finmeccanica [Электронный ресурс] - Режим доступа: http://www.finmeccanica.com. 


\section{Сведения об авторах / About authors}

Бровко Пётр Михайлович, соискатель кафедры экономики предприятия Школы экономики и менеджмента, Дальневосточный федеральный университет. 690922 Россия, г. Владивосток, о-в Русский, кампус ДВФУ, корпус G. E-mail: brovko.pm@dvfu.ru

Peter M. Brovko, Applicant for the Department of Economics of the Enterprise, School of Economics and Management, Far Eastern Federal University. Building G, FEFU campus, Russky Island, Vladivostok, Russia 690922.E-mail: brovko.pm@dvfu.ru

Карастелёв Борис Яковлевич, доктор технических наук, профессор, профессор кафедры экономики предприятия Школы экономики и менеджмента, Дальневосточный федеральный университет. 690922 Россия, г. Владивосток, о-в Русский, кампус ДВФУ, корпус G.

E-mail: karastelev.bya@dvfu.ru

Boris Ya. Karastelev, Doctor of Technical Sciences, Professor, Professor of the Department of Enterprise Economics, Far Eastern Federal University. Building G, FEFU campus, Russky Island, Vladivostok, Russia 690922.E-mail: karastelev.bya@dvfu.ru

Якубовский Юрий Владимирович, доктор технических наук, профессор, профессор кафедры экономики предприятия Школы экономики и менеджмента, Дальневосточный федеральный университет. 690922 Россия, г. Владивосток, о-в Русский, кампус ДВФУ, корпус G.

E-mail: yakubovskiy.yuv@dvfu.ru

Yuriy V. Yakubovskiy, Doctor of Technical Sciences, Professor, Professor of the Department of Enterprise Economics, Far Eastern Federal University. Building G, FEFU campus, Russky Island, Vladivostok, Russia 690922.E-mail: yakubovskiy.yuv@dvfu.ru 